University of Nebraska - Lincoln

DigitalCommons@University of Nebraska - Lincoln

\title{
Controllable energy absorption of double sided corrugated tubes under axial crushing
}

\author{
Hozhabr Mozafari \\ University of Nebraska-Lincoln, hmozafari2@unl.edu \\ Shengmao Lin \\ Xiamen University of Technology \\ Linxia Gu \\ University of Nebraska-Lincoln, gul@fit.edu
}

Follow this and additional works at: https://digitalcommons.unl.edu/mechengfacpub

Part of the Mechanics of Materials Commons, Nanoscience and Nanotechnology Commons, Other Engineering Science and Materials Commons, and the Other Mechanical Engineering Commons

Mozafari, Hozhabr; Lin, Shengmao; and Gu, Linxia, "Controllable energy absorption of double sided corrugated tubes under axial crushing" (2017). Mechanical \& Materials Engineering Faculty Publications. 253.

https://digitalcommons.unl.edu/mechengfacpub/253

This Article is brought to you for free and open access by the Mechanical \& Materials Engineering, Department of at DigitalCommons@University of Nebraska - Lincoln. It has been accepted for inclusion in Mechanical \& Materials Engineering Faculty Publications by an authorized administrator of DigitalCommons@University of Nebraska Lincoln. 


\title{
Controllable energy absorption of double sided corrugated tubes under axial crushing
}

\author{
Hozhabr Mozafari, ${ }^{1}$ Shengmao Lin, ${ }^{2}$ Gary C.P. Tsui, ${ }^{3}$ \& \\ Linxia $\mathrm{Gu}^{1}$
}

1 Department of Mechanical and Materials Engineering, University of NebraskaLincoln, Lincoln, NE 68588-0656, United States

2 School of Civil Engineering and Architecture, Xiamen University of Technology, PR China

3 Department of Industrial and Systems Engineering, The Hong Kong Polytechnic University, Hong Kong, PR China

Corresponding author — L. Gu, email lgu2@unl.edu

\begin{abstract}
To maximize the controllable energy absorption of corrugation troughs as observed in the single sided corrugated (SSC) tube, we proposed and tested a new structure design, i.e., double-sided corrugated (DSC) tube made of Al 6060-T6 aluminum alloy or CF1263 carbon/epoxy composite. Finite element models were developed to test the mechanical advantage of the DSC tube in comparison with both SSC and classical straight (S) tubes under axial crushing. Results have shown that the total absorbed energy of the DSC aluminum tube with 14 corrugations was 330\% and 32\% higher than that of the SSC tube with 14 corrugations and the S-tube, respectively. The initiation and progression of the crushing process for different tube configurations were characterized, leading to the mechanism of energy absorption. Plastic deformation in terms of PPEQ is the key parameter correlating with the energy absorption capacity. To overcome the lower specific absorbed energy (SAE) in the DSC tube compared to that in the S-tube, the CF1263 carbon/ epoxy composite laminate was adopted and the corresponding SAE was 5.9 times higher than that of the aluminum one. Moreover, the influence of the number of corrugations on the crushing behaviors of the DSC tube was also
\end{abstract}


inspected. A minimal straight tube section was suggested for a controllable smooth crushing behavior regardless of its advantage in SAE. This work might shed light on designing future thin-walled energy absorber devices with better control of crushing behaviors for minimal injuries and damages.

Keywords: Crashworthiness, Double-sided corrugated tube, Composites, Energy absorption, Finite element

\section{Introduction}

Structural crashworthiness is an extensive research area in optimizing the behaviors of energy absorbing systems. Subjected to external crushing, permanent plastic deformations were introduced in crashworthy components to dissipate dynamic energy, which depends on material compositions, various geometrical shapes, and fabrication processes. Specially thin-walled structures have attracted much attention due to their low cost, ease of fabrication and superior energy absorption efficiency [1-3]. Previous works have looked into crosssectional shapes [1,4], composite materials [5-7], and multi-step energy absorbing devices $[8,9]$. Thin-walled structures filled with aluminum honeycombs [10-16] and polymeric or metallic foams [17-20] as well as multi-cell tubes [21-25] have been suggested for better crashworthiness properties of energy absorbers. Composite materials have also demonstrated the mechanical advantages of crashworthiness over classical metals [26], i.e., crushing energy absorption per unit of mass [27-29]. For example, energy absorber devices made of carbon fiber reinforced plastic (CFRP) performed exceptionally well subjected to crushing loads [30]. Due to its lower density, higher specific strength, and superior crushing resistance, the CFRP has been widely utilized in high-end sports and/or electric vehicles [31-35]. Sun et al. [36] compared the crashworthiness of empty circular CFRP with CFRP/ aluminum/steel tubes filled with aluminum foam or aluminum honeycomb under axial quasi static crushing. It was found that most of the foam filled tubes collapse in a progressive mode, exhibiting noticeable merits in crashworthiness. Moreover, it was noted that the specific energy absorption of CFRP tubes filled with honeycomb was slightly lower than the empty counterparts but far better than those of all metal specimens. Hussein et al. [37] conducted experimental investigations to study the axial crushing behavior of aluminum honeycomb-filled square CFRP tubes. The mean crushing force and energy 
absorption by honeycomb-filled CFRP tubes were larger than those of corresponding hollow CFRP tubes. On the other hand, the specific energy absorption of aluminum honeycomb-filled CFRP tubes were found to be less than that of a hollow CFRP tube. Liu et al. [38] studied the effects of expanded polypropylene (EPP) foam filling on the mechanical properties of aluminum honeycomb panels. It was showed that the mean crushing strength and total absorbed energy in the axial tests increased with the foam filler; and the higher foam density the greater filling effect, whereas the specific absorbed energy remained unchanged with increase in the foam density. They also [39] deigned a lightweight EV body structure made of CFRP and evaluated its performance using a multiscale approach and the crashworthiness was compared with an identical body made of GFRP. The CFRP body structure was 28\% lighter than the GFRP, and the crashworthiness of the body structure increased. The carbon fiber composites also demonstrated their capacity as crushing energy absorbers with larger specific stiffness in a Formula SAE car [30].

Moreover, geometric modification from a straight tube (S-tube) to a single-sided radial corrugated tube (SSC) has shown a desirable smooth load-displacement behavior with minimal fluctuations [4047]. The introduction of corrugations helped in directing the crushing energy to the corrugation trough. Eyvazian et al. [48] showed that an SSC aluminum tube can enhance energy absorption up to $228 \%$ compared with an S-tube under lateral loading conditions. The energy absorption capacity of a S-tube subject to axial loading is approximately ten times, more than that under lateral loading conditions [49]. Wu et al. [50] performed a parametric study on collapse mode and energy absorption of corrugated tubes. However, it has been observed that the energy absorption of the SSC tube was even much less than an S-tube under axial loading conditions [40]. This was expected, due that the formation of plastic hinges in the S-tube demanded much more energy than guiding the deformation of corrugation troughs. Chen and Ozaki [49] have further illustrated that the patterns vary with the shape of the corrugations and the geometry of the structure. For a fixed length, the axisymmetric hinge formation could absorb more energy than the asymmetric one. Considering the controllable energy absorption of the SSC tube under axial loading, more attention was focused on the means to improve the energy absorption capacity of the SSC. 
In this work, we proposed an innovative structure design, referred to as double-sided corrugated tube (DSC), with the aim to provide more plastic deformation subjected to axial crushing and preserve the controllable energy absorption of the corrugation troughs. Within this regard, numerical models were developed to test the new tube designs following their validation against analytical solutions. A parametric study had been made in terms of geometry and materials through finite element analysis. Specifically, the axial crushing responses of DSC, SSC and S-tube made of classical aluminum alloy were compared. The DSC tube made of CF1263 carbon/epoxy composite, denoted as DSC-C, was characterized to show its crashworthy advantage. Moreover, the influence of the number of corrugations on the load-displacement behaviors of DSC tubes was investigated.

\section{Finite element model}

Nominal tube dimensions were adopted at $112 \mathrm{~mm}$ in length, $80 \mathrm{~mm}$ in diameter and $1 \mathrm{~mm}$ in thickness [49], regardless of detailed shape configurations, as shown in Fig.1. Corrugations were considered to be in sinusoidal form with corrugation length $\lambda_{c}$ and corrugation amplitude $a$. Since the tube was fully corrugated with 14 corrugations along the tube length, SSC, DSC or DSC-C tubes were also referred to as SSC-14, DSC-14, or DSC-14-C respectively.
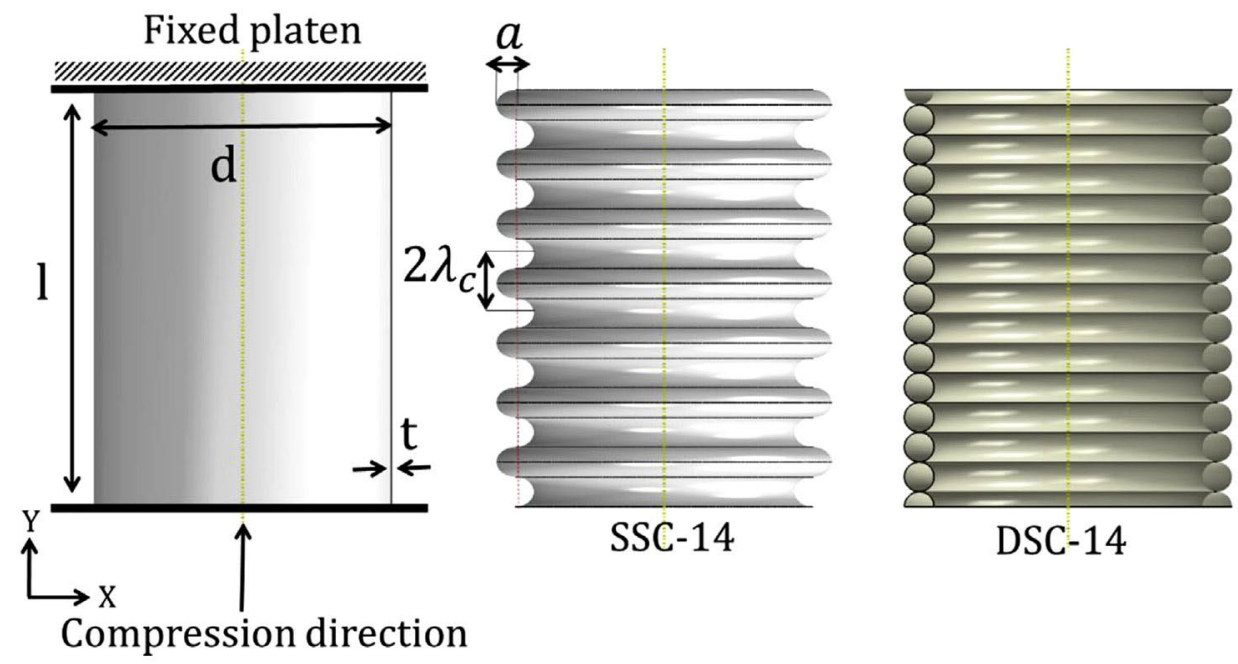

Fig. 1. Three dimensional tube configurations. Left, Straight tube with constrains; Middle, single-sided corrugated tube with corrugation parameters; Right, doublesided corrugated tube. 
Both ends of the tube were confined by two rigid plates. The top plate was fixed and the bottom one allowed the Y-direction translation only, with a displacement rate of $5 \mathrm{~mm} / \mathrm{min}$. The general frictionless node-to-surface contact was prescribed between the rigid plates and the tube. All tubes, except the composite one, were made of Al 6060-T6 aluminum alloy with Young's modulus of $71 \mathrm{GPa}$, Poisson's ratio of 0.33 , density of $2700 \mathrm{~kg} / \mathrm{m}^{3}$, yield strength of $160 \mathrm{MPa}$, and ultimate tensile strength of $200 \mathrm{MPa}$. The elastoplastic constitutive material model was adopted. For the composite DSC-14-C tube, CF1263 carbon/epoxy composite layup was chosen [51] with materials properties listed in Table 1. The Hashin progressive damage model was adopted and the damage is determined at the point when each of several damage criteria was met. Each damage criteria compares the calculated stresses against the strength properties of the respective material. Energy-based damage evolution was employed to encompass strain softening response of CFRP composite. The stacking sequence of the composite tube was [ \pm 45$]$ with the thickness of each layer at $0.25 \mathrm{~mm}$. The laminate had four layers and a thickness of 1 $\mathrm{mm}$ in total. All tubes were meshed using S4R linear shell elements with five integration points. The shell element provides accurate modeling without greatly increasing the computational time needed for each run. Mesh convergence analysis were conducted (Fig. 2) and the $1 \mathrm{~mm}$ element size was chosen.

Table 1. Mechanical properties of laminate composite material CF1263.

\begin{tabular}{|c|c|c|c|c|c|c|c|c|c|c|c|c|c|}
\hline \multirow[t]{2}{*}{$\begin{array}{l}\text { Density } \\
\left(\mathrm{kg} / \mathrm{m}^{3}\right)\end{array}$} & \multicolumn{3}{|c|}{$\begin{array}{c}\text { Elastic } \\
\text { modulus (GPa) }\end{array}$} & \multicolumn{3}{|c|}{$\begin{array}{c}\text { Shear } \\
\text { modulus (GPa) }\end{array}$} & \multicolumn{3}{|c|}{$\begin{array}{l}\text { Poisson's } \\
\text { ratio }\end{array}$} & \multicolumn{2}{|c|}{$\begin{array}{c}\text { Tensile } \\
\text { strength (MPa) }\end{array}$} & \multicolumn{2}{|c|}{$\begin{array}{l}\text { Compressive } \\
\text { strength (MPa) }\end{array}$} \\
\hline & $E_{x}$ & $E_{y}$ & $E_{z}$ & $G_{x y}$ & $G_{y z}$ & $G_{x z}$ & $v_{x y}$ & $v_{y z}$ & $v_{x z}$ & Fill & Wrap & Fill & Wrap \\
\hline 520 & 58.36 & 48.42 & 10.66 & 5.84 & 3.65 & 3.65 & 0.12 & 0.45 & 0.45 & 885 & 1018 & 513 & 542 \\
\hline
\end{tabular}




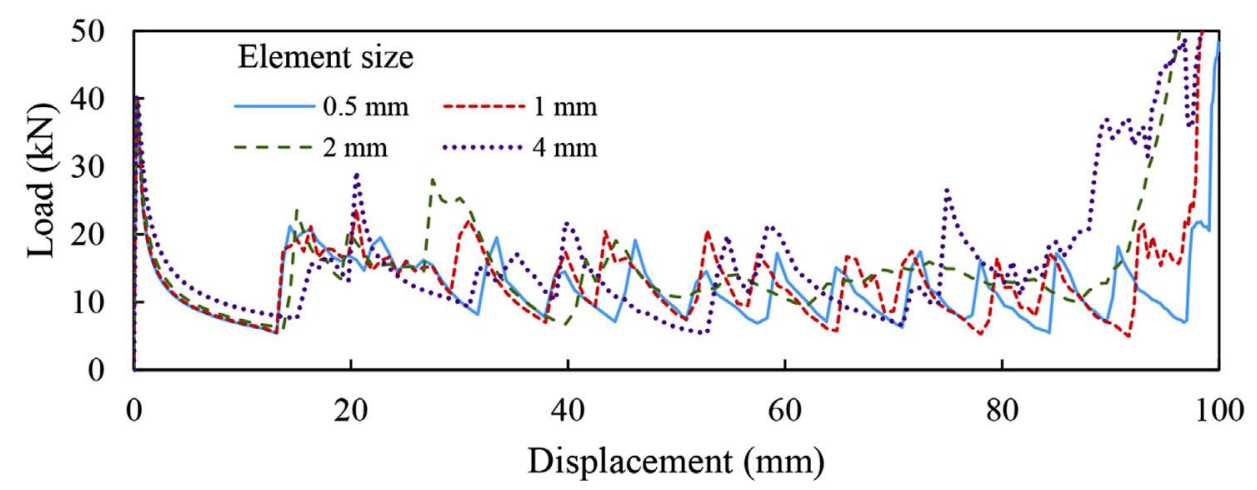

Fig. 2. Load-displacement response of $\mathrm{S}$ tube for different element sizes.

\section{Results and discussions}

\subsection{Verification of FE model}

The analytical solution for an S-tube based on the kinetic approach [49] was used to validate our FE model results. The average compressive force over the whole crushing process could be calculated by

$$
\begin{aligned}
\lambda & =0.920 \sqrt{2 R t} \\
\frac{P_{\text {ave }}}{M_{0}} & =\frac{25.23 \sqrt{2 R / t}+11.9}{0.86-0.568 \sqrt{t / 2 R}}
\end{aligned}
$$

Where $M_{0}=\sigma_{0} t^{2} / 4$ is the fully plastic moment per unit length, $\sigma_{0}$ is the energy equivalent flow stress which is estimated as the $0.2 \%$ of yield strength [52], $\sigma_{u}$ is the ultimate strength, and $\lambda$ is the half-wavelength of the wrinkle. $R$ and $t$ are radius and thickness of tube, respectively.

The average compressive force $P_{\text {ave }}$ from our model was calculated by dividing the total absorbed energy, i.e., the area under the loaddisplacement diagram (Fig. 3), by the displacement magnitude just before the densification point [49].

Moreover, $\lambda$ was obtained by measuring the half-formed wrinkle length of the hinge. The calculated reaction force and the half-formed wrinkle length for the S-tube were $12.84 \mathrm{kN}$ and $9.26 \mathrm{~mm}$, respectively. The corresponding analytical results from Equations (1) \& (2) were $14.91 \mathrm{kN}$ and $8.228 \mathrm{~mm}$. The differences between the simulation and 


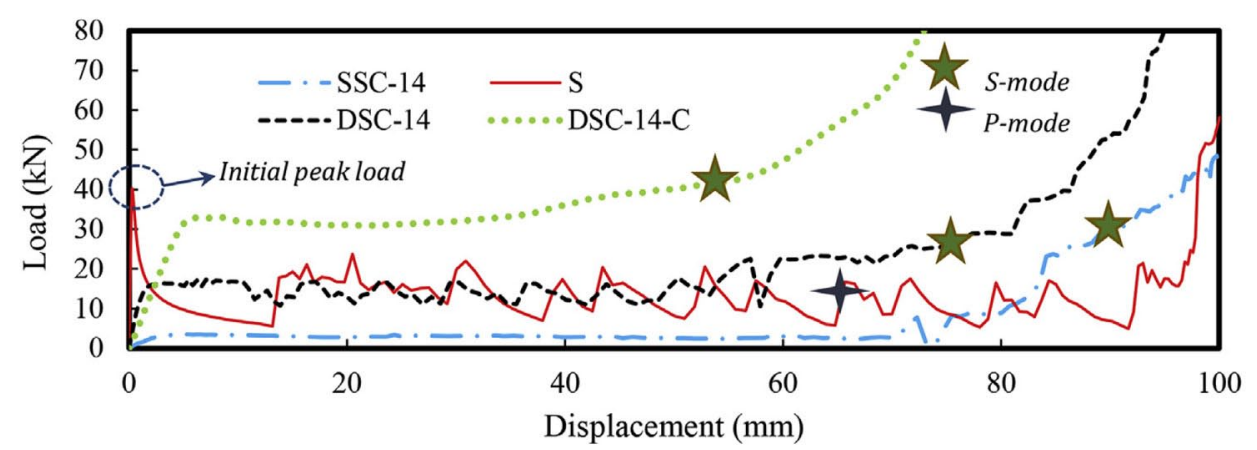

Fig. 3. Load-displacement diagrams of the tubes under axial compressive loading.

the analytical solutions were $16 \%$ and $12.5 \%$, respectively. These variations could be explained by the assumptions used in the kinetic approach [30]. In addition, the modeling framework for composite materials was validated in our previous work $[7,53]$.

\subsection{Mechanical advantage of double-sided corrugated tube}

To improve the energy absorption capacity of the SSC without scarifying its controllable energy absorption of corrugation troughs, we tried a variety of corrugation shapes, such as moon shape, half-circular, diamond and half-diamond before finding the desirable DSC tube. The mechanical performance of the proposed DSC-14 tube was demonstrated by comparing it with existing tubes such as the SSC-14 and S-tube. Their load-displacement behaviors were depicted in Fig. 3. It is clear that the DSC-14 could take more loads and thus absorb more crushing energy than both the SSC-14 and Stube, especially at large displacement. The load fluctuation of the corrugated tubes was also relatively small compared to the S-tube, which allowed better regulation of their energy absorption behaviors.

The advantage of the DSC-14 over the SSC-14 and S-tube could be visualized from the snapshots of tube compression, as shown in Fig. 4. The contour plot of the equivalent plastic strain (PEEQ) in Fig. 4 shows that the PEEQ concentrated around the folds, whose geometry parameters were the critical design factors for optimization of energy absorption ability. The percentage of DSC-14 tube surface with plastic deformation (PEEQ $\geq 0.1 \%$ ) just before densification was $97 \%$, while it was $68 \%$ for the SSC-14 tube, indicating a $170 \%$ relative increase. 

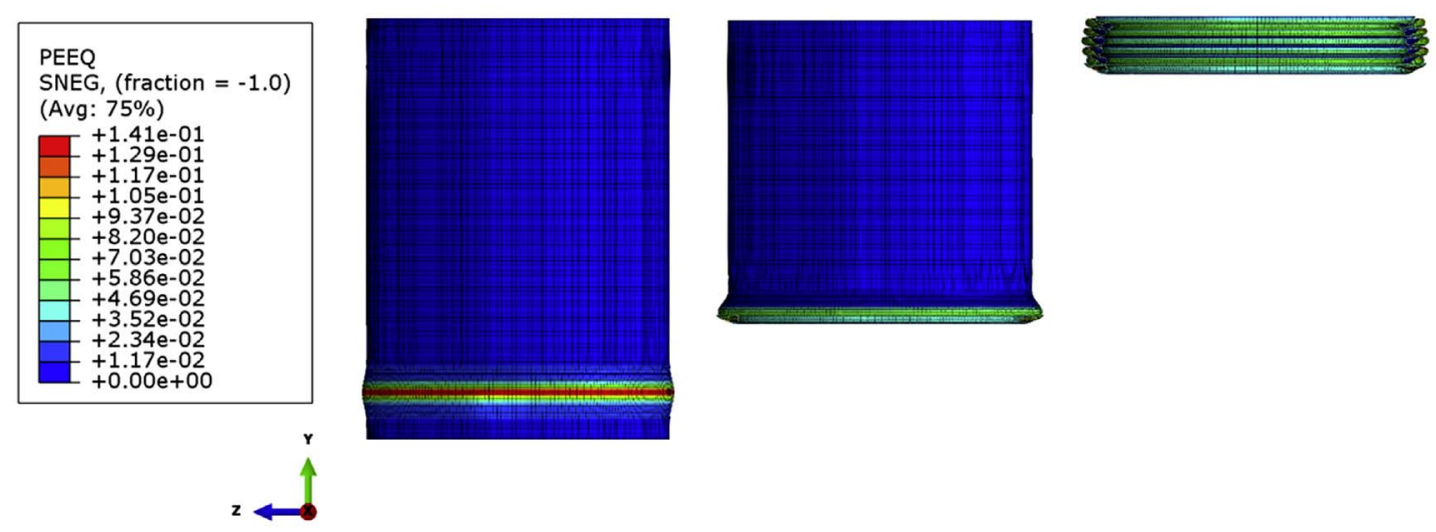

(a) STube
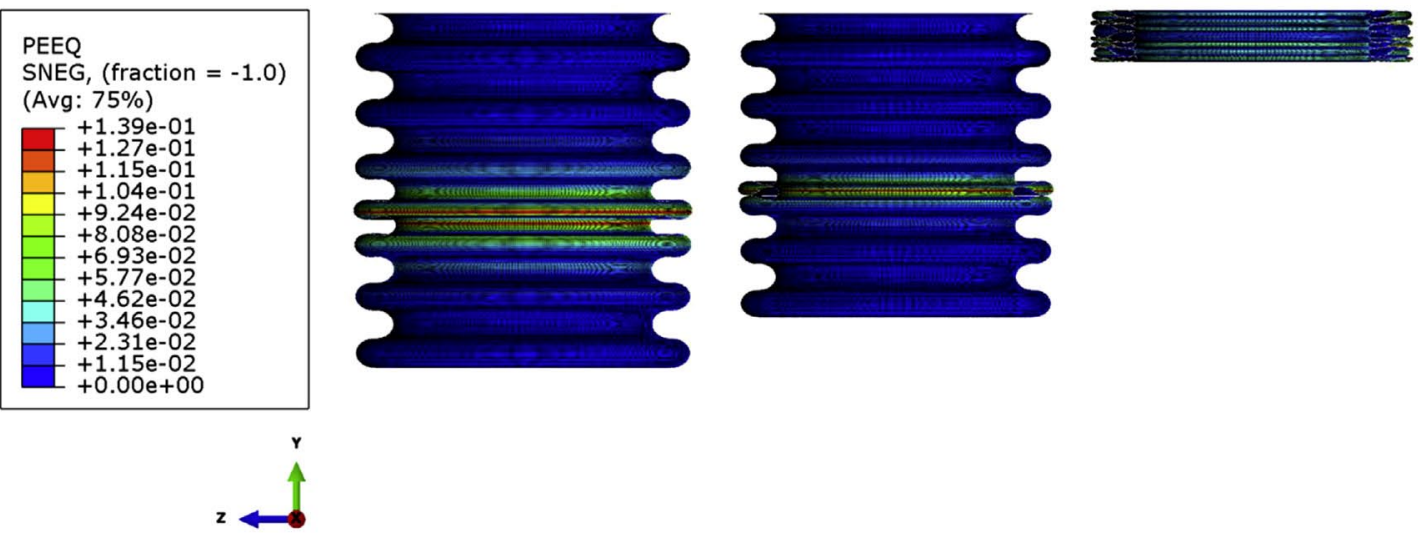

(b) SSC-14 Tube
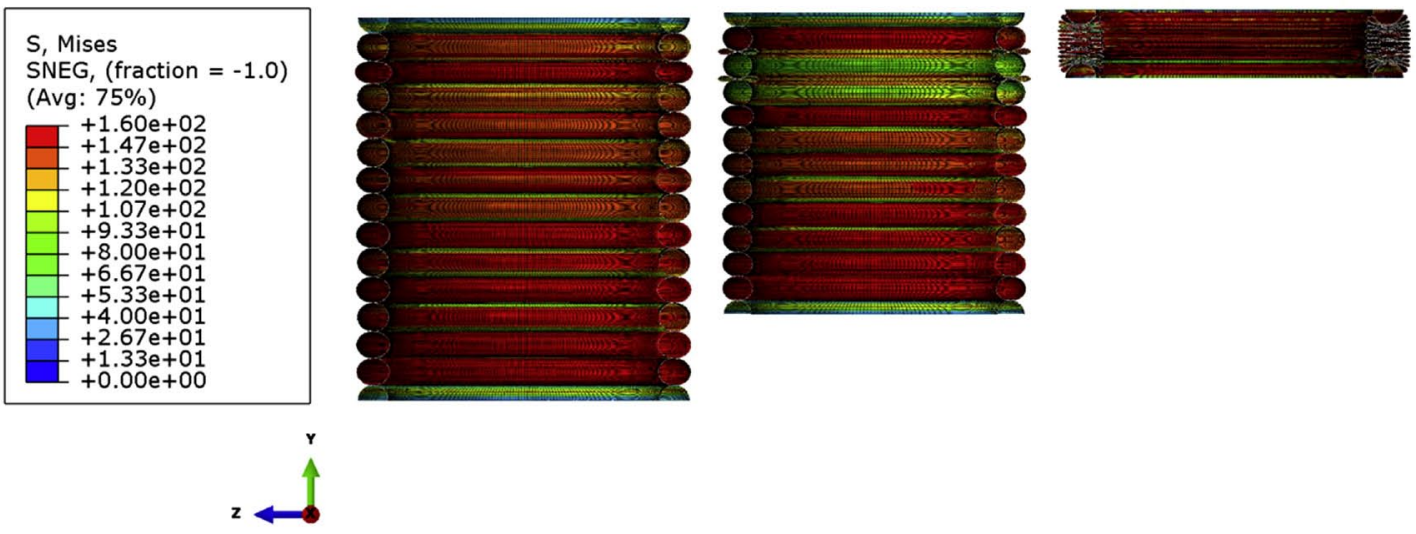

(c) DSC-14 Tube 
Fig. 4 (opposite). Equivalent Plastic Strain (PEEQ) contours. (a) S tube: Left, first fold initiation at crushing displacement of $0.37 \mathrm{~mm}$; Middle, second fold development at displacement of $31.75 \mathrm{~mm}$; Right, final compressed state with crushing displacement of 97.83; (b) SSC-14 tube: Left, first fold initiation at crushing displacement of $17 \mathrm{~mm}$; Middle, second fold development at displacement of $27.7 \mathrm{~mm}$; Right, final compressed state with crushing displacement of $89 \mathrm{~mm}$; (c) DSC-14 tube: Left, first fold initiation at crushing displacement of $11 \mathrm{~mm}$; Middle, second fold development at displacement of $23.5 \mathrm{~mm}$; Right, final compressed state at crushing displacement of $79.8 \mathrm{~mm}$.

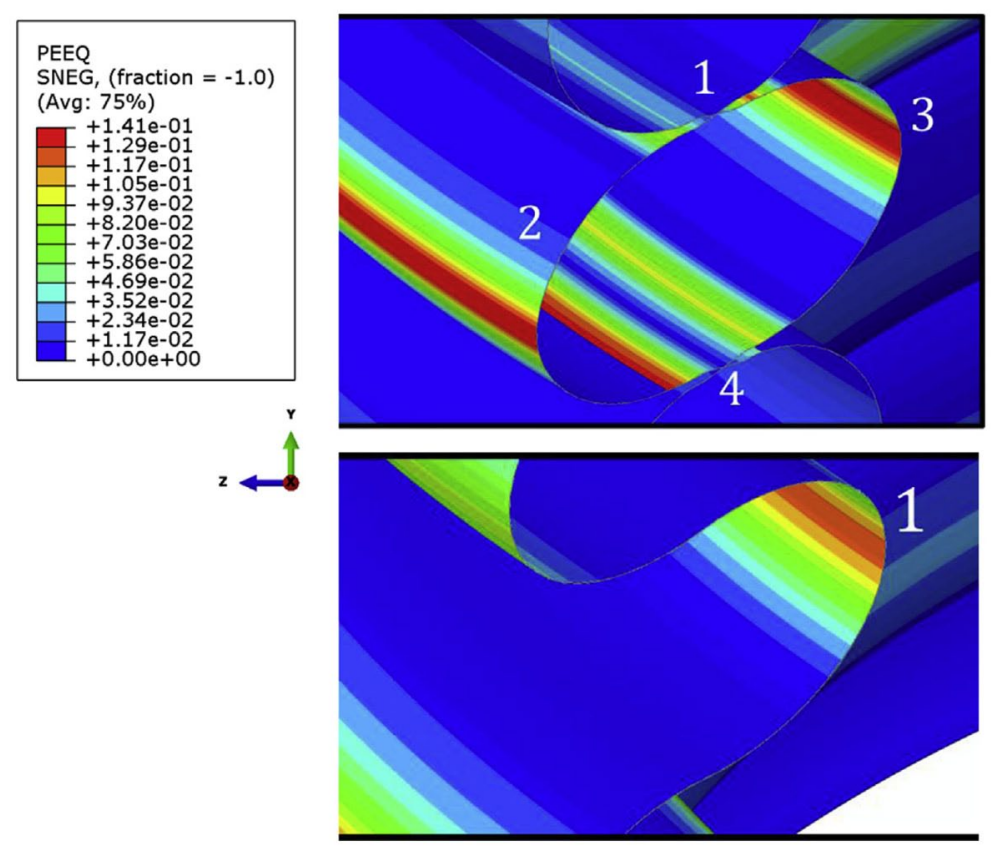

Fig. 5. Folding schematics of DSC-14 (top) and SSC-14 (bottom).

During the crushing of each corrugation, there are four plastic hinges for DSC-14 while there is only 1 plastic hinge for SSC-14 (Fig. 5). Accumulation of these plastic hinges indicates the higher plastic deformation of DSC-14 compared with SSC- 14 .

The initiation of both first and second folds as well as the final compressed state were illustrated. For the S-tube, a single abrupt hinge was initiated near the crushing interface, i.e., the movable plate, when the plate displacement reached $0.37 \mathrm{~mm}$. This first fold or hinge progressed until collapse (Fig. 7), and then the new hinge was developed and so on. The PEEQ history at one specific point located within the 


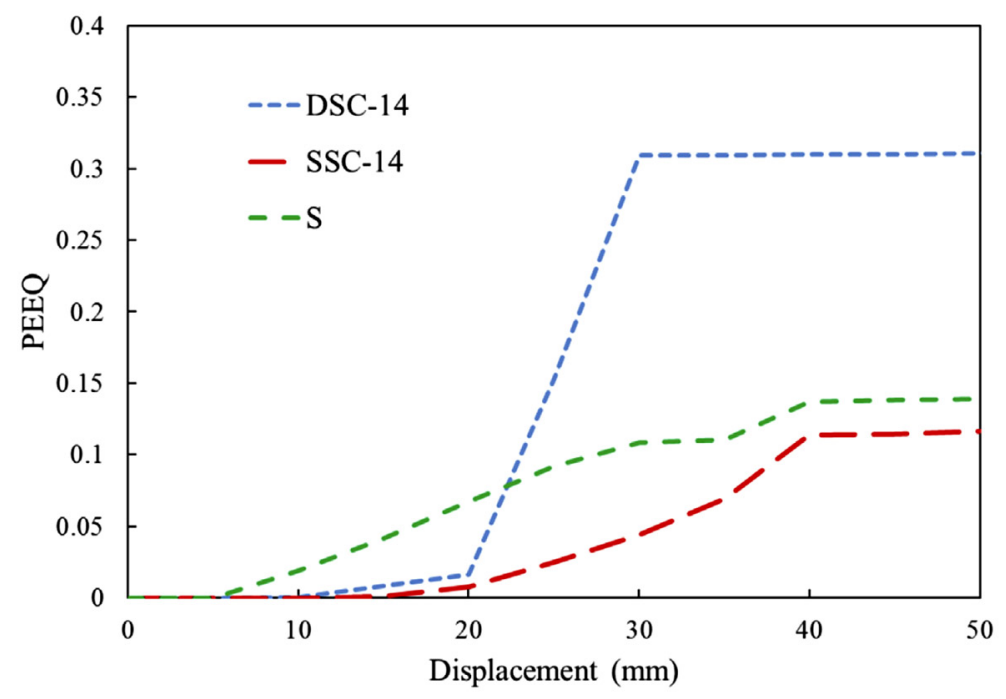

Fig. 6. The (PEEQ) history at one specific region (first formed wrinkle) for S, SSC14 and DSC-14 tubes.

formation of the first fold was plotted in Fig. 6. The progression of the first fold from initiation to collapse resulted in the increase in the PEEQ and then stayed at a plateau.

The second fold initiated at a plate displacement of $31.8 \mathrm{~mm}$, and the S-tube was completely crushed at a displacement of $97.8 \mathrm{~mm}$. The location of the first fold agreed with the previous report [49]. In addition, the hinge collapse pattern led to a changing load fluctuation in the S-tube, also referred to as P-mode deformation, as labeled in Fig. 3. This kind of axial behavior could be explained by the first hinge induced abrupt stress concentration, which resulted in the sharp rise in its load-displacement behavior and the plastic deformation regime.

The corrugated tubes exhibit a gradual increase in compression loading with a larger displacement, labeled as S-mode behaviors in Fig. 3 and illustrated by the PEEQ contours in Fig. 4 (b \& c). The crushing load induced large irreversible plastic deformation, which determined the energy absorption capacity of the tubes. The first two folds initiated at a plate displacement of $17.0 \mathrm{~mm}$ and $27.7 \mathrm{~mm}$ for the SSC14 tube, and $11.0 \mathrm{~mm}$ and $23.5 \mathrm{~mm}$ for the DSC-14 tube, respectively. The complete crushed state was reached at a plate displacement of $89.0 \mathrm{~mm}$ and $79.8 \mathrm{~mm}$ for the DSC-14 and the SSC-14, respectively. It is clear that the PEEQ region was located near the crushing interface for both DSC-14 and S-tube, but for the SSC-14, it initiated from the middle of the tube. The plastic hinge formation occurred more 

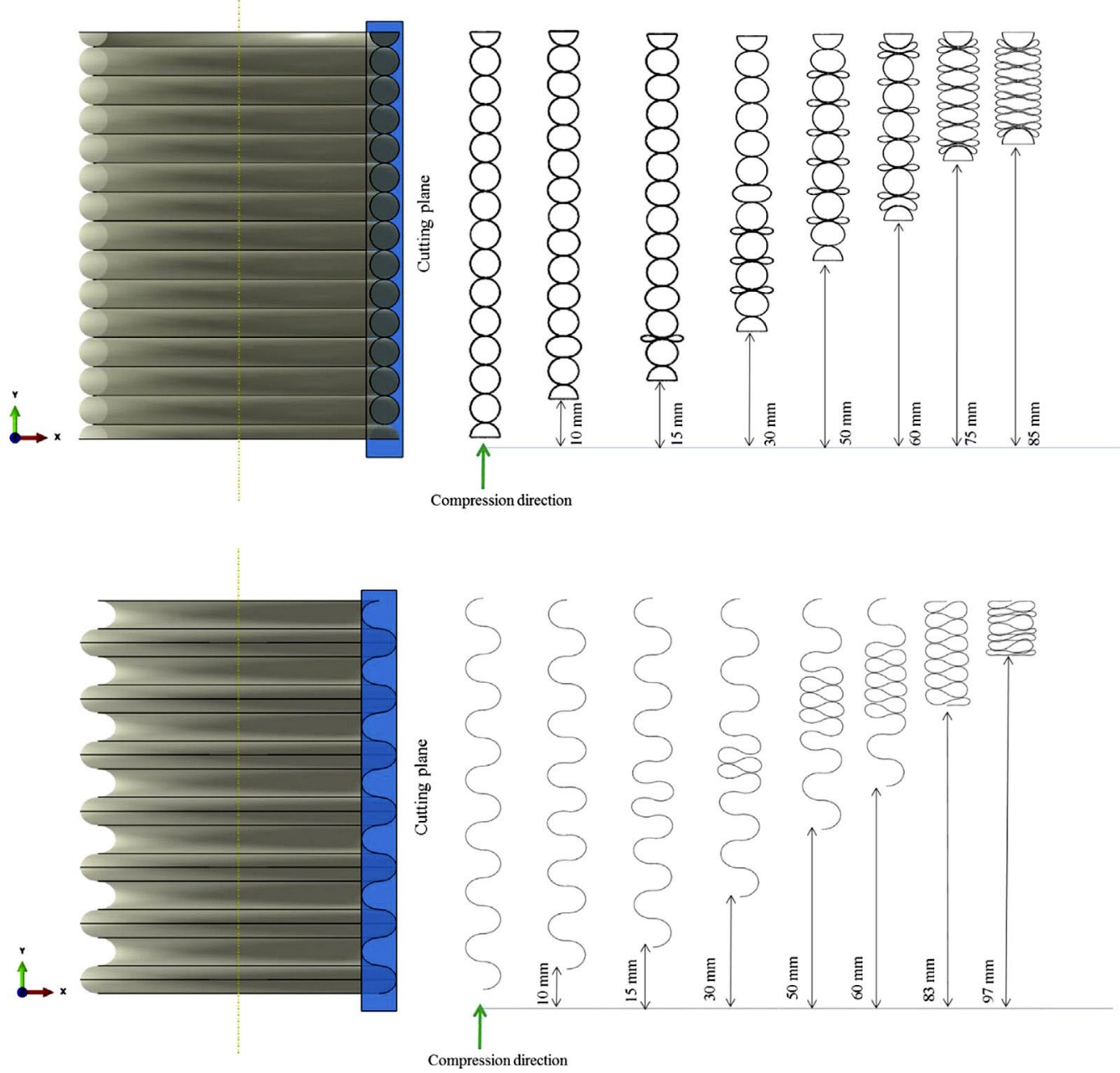

Fig. 7. Crushing progression of DSC-14 (Top) and SSC-14 tube (Bottom).

uniformly through the tube length. There was minimal fluctuation in the load-displacement response during crushing, which is associated with a reduced risk of injuries. This is a desirable characteristic in crashworthy design. It is also interesting to observe that the initiation of the first crushing fold for the corrugated tubes occurred relatively later than for the S-tube. However, it took much less crushing displacement, but more energy, to form the second fold in the DSC14 tube in the than other two tubes. Besides, the final crushed state of the DSC-14 tube was relatively longer than the other two. This indicates that the axial deformation of the DSC tube could play an important role in crashworthy design [40]. 

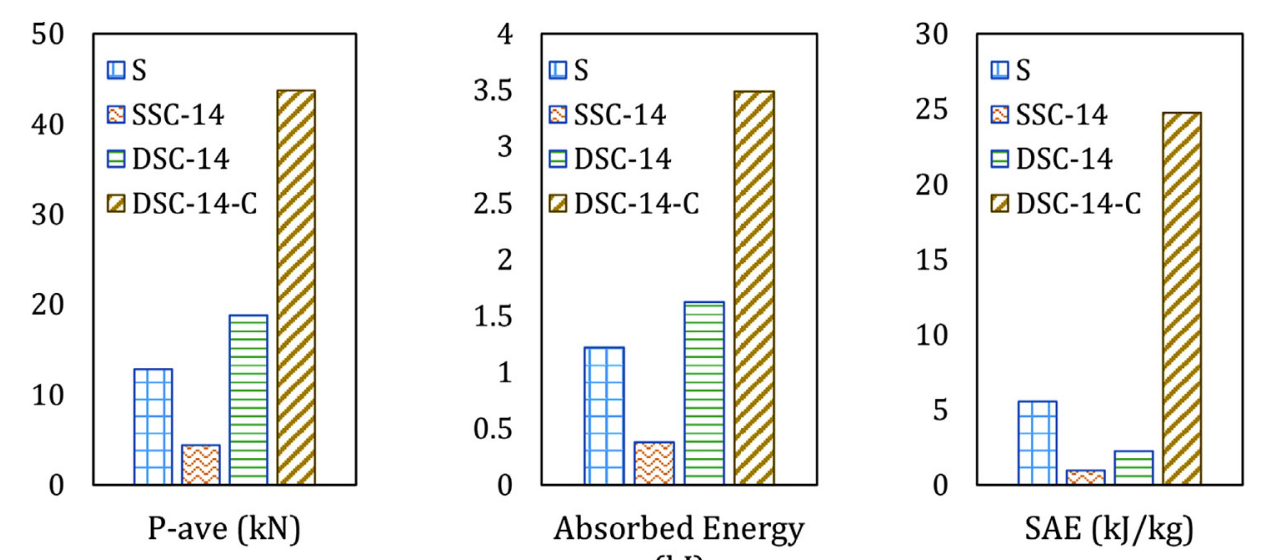

$(\mathrm{kJ})$

Fig. 8. Crashworthiness properties of tube structures.

It is clear that the energy absorption capability of the SSC-14 tube subjected to axial crushing is notably lower than the S-tube with identical dimensions (Fig. 3). This agrees with the work by Eyvazian et al. [40]. As expected, more crushing load could be absorbed in the S-tube due to the bending of a straight wall, resulting in more plastic bending energy. On the other hand, the load and dissipated energy was reduced in the SSC-14 due to the existence of radial corrugations [49]. This indicated that the formation of hinges in the S-tube demanded much more energy than guiding the deformation of single-sided corrugation troughs. For double-sided corrugations, the additional symmetric side reinforced the structural stiffness of the tube and thus altered the deformation pattern of the tube as illustrated in Fig. 7.

At the compression displacement of $10 \mathrm{~mm}$, the second corrugation near the crushing interface, i.e., the movable plate experienced relatively larger distortion and crushing before the initiation of the second plastic hinges, which was spaced in every other corrugation. This pattern of crushing behavior repeated until reaching the other end of the tube. Then the second level of crushing was initiated at the compression displacement of $60 \mathrm{~mm}$. At this stage, the uncrushed corrugations underwent plastic deformation one by one. The corrugations underwent plastic folding along with the densification of the tube. Moreover, the double-sided corrugations were able to produce four plastic hinges at each corrugation, compared to only one plastic hinges for the SSC-14. This way, the tube resistance against crushing 


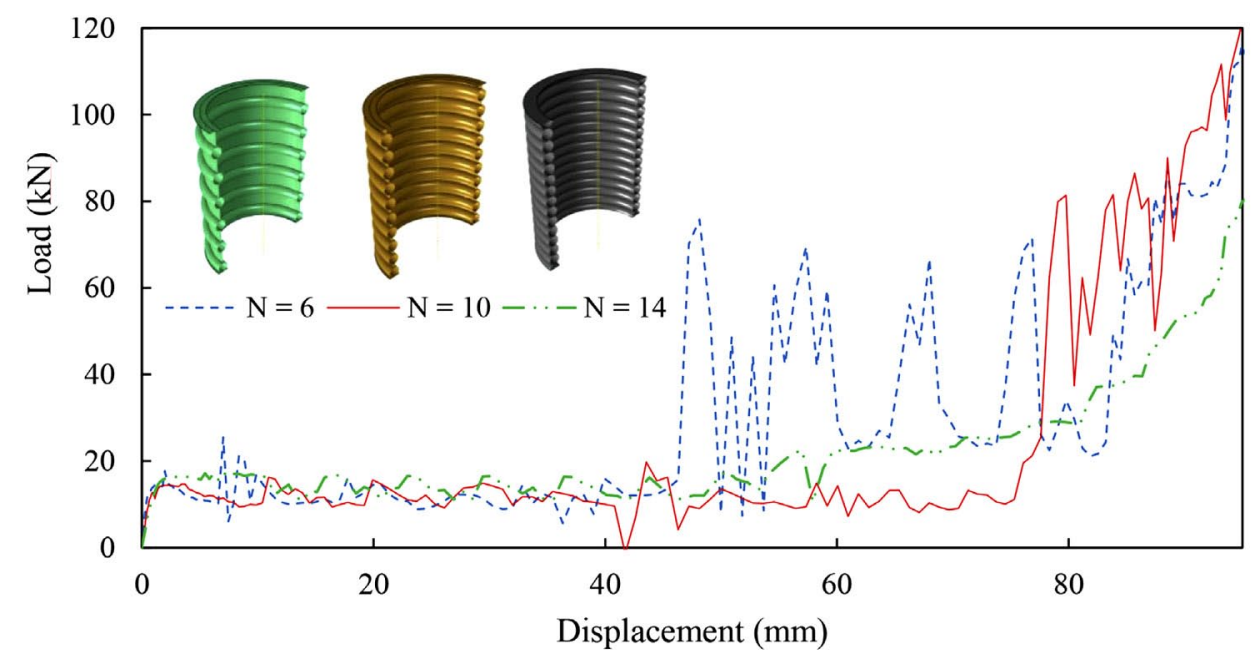

Fig. 9. Corrugation spacing affect the crushing responses of DSC tubes.

increased, resulting in a larger percentage of plastic zone and therefore a higher absorbed energy.

The crashworthiness parameters for each tube were characterized in Fig. 8. Specifically, the average compressive force over the whole crushing process was 18.82, 4.38, and $12.84 \mathrm{kN}$ for the DSC-14, SSC14 and $S$-tube, respectively. The corresponding total absorbed energy, i.e., the area below the load-displacement curve, was 1.62, 0.38, and $1.22 \mathrm{~kJ}$. The specific absorbed energy (SAE), defined as the total absorbed energy per unit mass, was calculated as 2.25, 0.97, and 5.55 $\mathrm{kJ} / \mathrm{kg}$ for the DSC-14, SSC-14 and S-tube, respectively. Our proposed DSC-14 tube demonstrated a 32\% greater increase in energy absorption than the S-tube with the same nominal dimensions. However, the SAE of the DSC-14 is approximately $40 \%$ of the one for the S-tube. To improve the SAE of the DSC-14, a composite tube, denoted as DSC14-C, was then investigated.

\subsection{Composite DSC-14 tube}

A dramatic increase in the load bearing capacity of the DSC-14-C was observed in comparison with the aforementioned tubes. The crashworthiness parameters for the DSC-14-C tube were $43.71 \mathrm{kN}$ for the average compressive force over the whole crushing process, $3.49 \mathrm{~kJ}$ for the total absorbed energy, and $24.75 \mathrm{~kJ} / \mathrm{kg}$ for the SAE. The change 


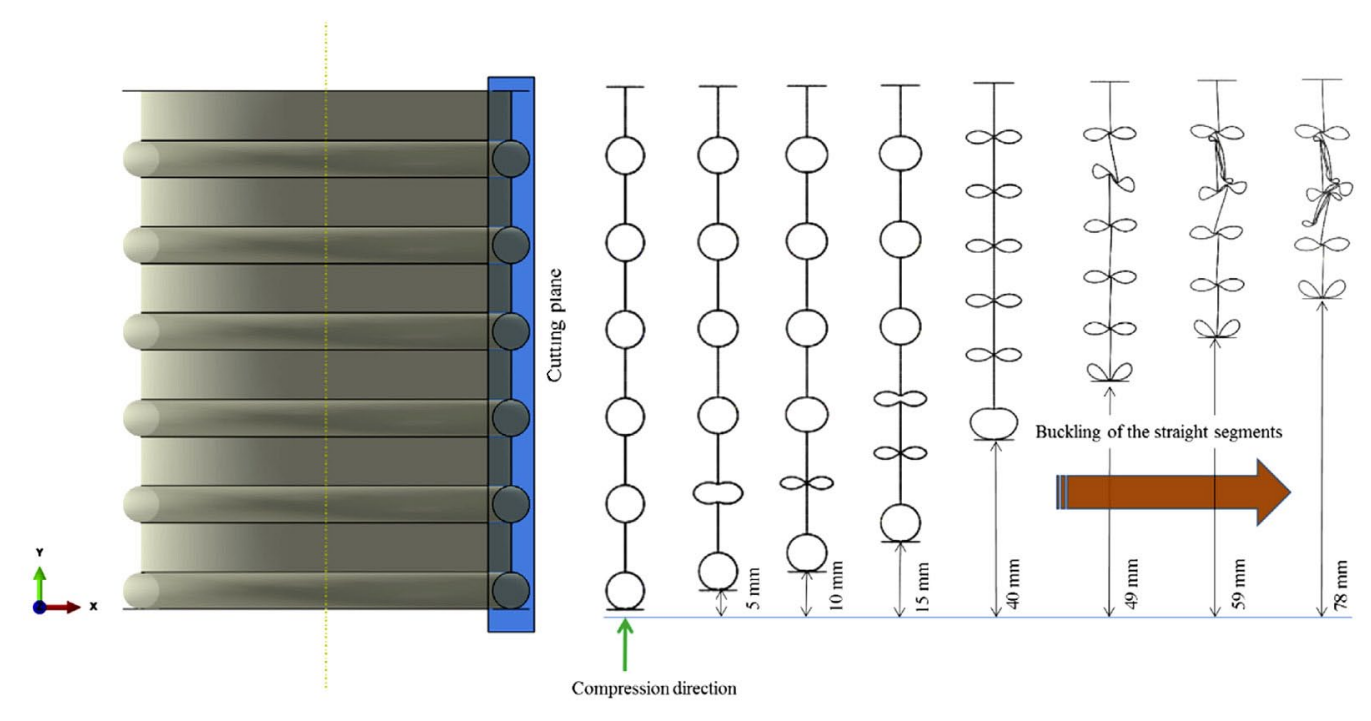

Fig. 10. Crushing progression of DSC-6 tube.

of tube materials from Al 6060-T6 aluminum alloy to CF1263 carbon/ epoxy composite laminate doubled the crashworthiness parameters in terms of the average compression force and the total absorbed energy, and boosted the SAE by eleven times. The DSC-14-C had obvious crashworthiness advantages over the S-tube. The crushing progression of the DSC-14-C is similar to the DSC-14 as shown in Fig. 4. The specific absorbed energy of the DSC-14 is $59 \%$ lower than that of the S-tube. The SAE value of the DSC-14-C is ten times higher than the DSC-14 and 346\% larger than the simple straight tube, S-tube.

\subsection{Effect of corrugation spacing on the performance of the DSC tube}

The role of corrugation spacing on the crashworthiness of DSC tubes was also studied as shown in Fig. 9. The nominal dimension of the tube remained the same. The number of corrugations for the aluminum alloy DSC tube was altered from 14 to 6 or 10, denoted as DSC- 6 and DSC-10, respectively. As the number of corrugations increased from 6 up to 14, the corrugation spacing, i.e., the straight tube segment linking the corrugations shortened from $20 \mathrm{~mm}$ to $0 \mathrm{~mm}$. Due to the corrugation spacing, relatively larger load fluctuations were observed in both the DSC- 6 and the DSC-10, which were initiated at the crushing displacement of $49 \mathrm{~mm}$ and $79 \mathrm{~mm}$, respectively. There is not 
any load fluctuation for fully corrugated DSC-14 tube. This indicated that the straight tube segment induced large load fluctuations during crushing, which might pose a safety threat to passengers, if any. Even though longer straight connectors resulting in a larger energy absorption, but less smooth crushing behavior is induced.

The mechanism could be well demonstrated by the crushing progression of the DSC- 6 tube (Fig. 10). Prior to the compression displacement of $40 \mathrm{~mm}$, the corrugations were plastically hinged one by one from the interface until reaching the other end of the tube, which correlated with the small fluctuations of load between $11 \mathrm{kN}$ and 14 $\mathrm{kN}$ in Fig. 10. At the compression displacement of $49 \mathrm{~mm}$, the first large load fluctuation between $14 \mathrm{kN}$ and $75 \mathrm{kN}$ was observed corresponding to the plastic buckling of straight wall segments. Similar behavior happened for the DSC-10.

\section{Conclusions}

Conventional single-sided corrugated aluminum tubes have demonstrated a desirable smooth load-displacement behavior, but at the cost of a lower energy absorption capacity, compared with the straight tube. In this work, we proposed and tested a DSC tube made of aluminum alloy or CF1263 carbon/epoxy composite. The aim was to improve the energy absorption capacity as well as preserve the controllable smooth crushing behavior, which is negatively associated with the safety threat to passengers. Finite element models were developed to test the new tube design following its validation against analytical solutions.

We have demonstrated the mechanical advantage of the DSC tubes over both SSC and S-tube under axial crushing. Specifically, the absorbed energy of the DSC-14 tube was 330\% and 32\% higher than that of the SSC tube and S-tube, respectively. However, due to the additional mass in the DSC-14 tube, its specific absorbed energy was $59 \%$ lower than that of the S-tube. The change of DSC-14 tube materials from Al 6060-T6 aluminum alloy to CF1263 carbon/epoxy composite laminate could boost its absorbed energy and specific absorbed energy up to $186 \%$ and $346 \%$ higher than that of the Stube, respectively. The mechanism of energy absorption for different tube 
configurations was inspected. The plastic deformation in terms of PPEQ is the key parameter correlating with the energy absorption capacity. Moreover, the influence of number of corrugations on the loaddisplacement behaviors of the DSC tube was quantified. Results suggested using a thin-walled tube design with minimal straight sections for a controllable smooth crushing behavior, even though minimal straight sections resulted in less SAE. These results could be further verified in crushing experiments of DSC tube, especially composite ones. In addition, the optimization of both geometrical parameters and material properties for the performance of the DSC-tube could be conducted [54]. In summary, the proposed DSC tube might shed light on the design of a thin-walled energy absorber device in transportation industries for mitigation of damages and injuries.

Acknowledgments - This work was partially supported by the Department of Mechanical and Materials Engineering at the University of Nebraska-Lincoln. The authors also thank Ms. Heidi Brauning for proofreading this manuscript.

\section{References}

[1] Alghamdi AAA. Collapsible impact energy absorbers: an overview. Thin-Walled Struct 2001;39(2):189-213.

[2] Mahdi E, Hamouda AMS. Energy absorption capability of composite hexagonal ring systems. Mater Des 2012;34:201-10.

[3] Mamalis AG, Manolakos DE, Demosthenous GA, Johnson W. Axial plastic collapse of thin bi-material tubes as energy dissipating systems. Int J Impact Eng 1991;11(2):185-96.

[4] Mamalis AG, Manolakos DE, Ioannidis MB, Kostazos PK, Dimitriou C. Finite element simulation of the axial collapse of metallic thin-walled tubes with octagonal cross-section. Thin-Walled Struct 2003;41(10):891-900.

[5] Bisagni C, Di Pietro G, Fraschini L, Terletti D. Progressive crushing of fiber-reinforced composite structural components of a Formula One racing car. Compos Struct 2005;68(4):491-503.

[6] Davoodi M, Sapuan S, Yunus R. Conceptual design of a polymer composite automotive bumper energy absorber. Mater Des 2008;29(7):1447-52.

[7] Hua Y, Akula PK, Gu L. Experimental and numerical investigation of carbon fiber sandwich panels subjected to blast loading. Compos Part B Eng 2014;56: 456-63. 
[8] Sun G, Li G, Stone M, Li Q. A two-stage multi-fidelity optimization procedure for honeycomb-type cellular materials. Comput Mater Sci 2010;49(3):500-11.

[9] Liao X, Li Q, Yang X, Li W, Zhang W. A two-stage multi-objective optimisation of vehicle crashworthiness under frontal impact. Int J Crashworthiness 2008;13(3):279-88.

[10] Wang Z, Liu J, Lu Z, Hui D. Mechanical behavior of composited structure filled with tandem honeycombs. Compos Part B Eng 2017;114:128-38.

[11] Liu Q, Mo Z, Wu Y, Ma J, Pong Tsui GC, Hui D. Crush response of CFRP square tube filled with aluminum honeycomb. Compos Part B Eng 2016;98:406-14.

[12] Wang Z, Yao S, Lu Z, Hui D, Feo L. Matching effect of honeycomb-filled thinwalled square tube-experiment and simulation. Compos Struct 2016;157: 494-505.

[13] Wang Z, Tian H, Lu Z, Zhou W. High-speed axial impact of aluminum honeycomb - experiments and simulations. Compos Part B Eng 2014;56:1-8.

[14] Wang Z, Liu J, Hui D. Mechanical behaviors of inclined cell honeycomb structure subjected to compression. Compos Part B Eng 2017;110:307-14.

[15] Sun G, Jiang H, Fang J, Li G, Li Q. Crashworthiness of vertex based hierarchical honeycombs in out-of-plane impact. Mater Des 2016;110:705-19.

[16] Fang J, Sun G, Qiu N, Pang T, Li S, Li Q. On hierarchical honeycombs under out-of-plane crushing. Int J Solids Struct 2017. https://doi.org/10.1016/ j.jjsolstr.2017.08.013 (in press).

[17] Othman A, Abdullah S, Ariffin AK, Mohamed NAN. Investigating the crushing behavior of quasi-static oblique loading on polymeric foam filled pultruded composite square tubes. Compos Part B Eng 2016;95:493-514.

[18] Fang J, Gao Y, An X, Sun G, Chen J, Li Q. Design of transversely-graded foam and wall thickness structures for crashworthiness criteria. Compos Part B Eng 2016;92:338-49.

[19] An X, Gao Y, Fang J, Sun G, Li Q. Crashworthiness design for foam-filled thinwalled structures with functionally lateral graded thickness sheets. Thin- Walled Struct 2015;91:63-71.

[20] Xiao Z, Fang J, Sun G, Li Q. Crashworthiness design for functionally graded foam-filled bumper beam. Adv Eng Softw 2015;85:81-95.

[21] Fang J, Sun G, Qiu N, Steven GP, Li Q. Topology optimization of multicell tubes under out-of-plane crushing using a modified artificial bee colony algorithm. J Mech Des 2017;139(7). 071403-071403-16.

[22] Pang T, Li Y, Kang H, Sun G, Fang J, Li Q. On functionally-graded crashworthy shape of conical structures for multiple load cases. J Mech Sci Technol 2017;31(6):2861-73.

[23] Fang J, Gao Y, Sun G, Qiu N, Li Q. On design of multi-cell tubes under axial and oblique impact loads. Thin-Walled Struct 2015;95:115-26.

[24] Qiu N, Gao Y, Fang J, Feng Z, Sun G, Li Q. Theoretical prediction and optimization of multi-cell hexagonal tubes under axial crashing. Thin-Walled Struct 2016;102:111-21. 
[25] Qiu N, Gao Y, Fang J, Feng Z, Sun G, Li Q. Crashworthiness analysis and design of multi-cell hexagonal columns under multiple loading cases. Finite Elem Analysis Des 2015;104:89-101.

[26] Yan L, Chouw N, Jayaraman K. Lateral crushing of empty and polyurethanefoam filled natural flax fabric reinforced epoxy composite tubes. Compos Part B Eng 2014;63:15-26.

[27] Mahdi E, Hamouda A, Mokhtar A, Majid D. Many aspects to improve damage tolerance of collapsible composite energy absorber devices. Compos Struct 2005;67(2):175-87.

[28] Thornton P, Harwood J, Beardmore P. Fiber-reinforced plastic composites for energy absorption purposes. Compos Sci Technol 1985;24(4):275-98.

[29] Thornton PH, Edwards P. Energy absorption in composite tubes. J Compos Mater 1982;16(6):521-45.

[30] Obradovic J, Boria S, Belingardi G. Lightweight design and crash analysis of composite frontal impact energy absorbing structures. Compos Struct 2012;94(2):423-30.

[31] Seo SI, Kim JS, Cho SH, Kim SC. Manufacturing and mechanical properties of a honeycomb sandwich panel. Mater Sci Forum 2008;580-582:85-8.

[32] Kim J-S, Lee S-J, Shin K-B. Manufacturing and structural safety evaluation of a composite train carbody. Compos Struct 2007;78(4):468-76.

[33] Kim J-S, Jeong J-C. Natural frequency evaluation of a composite train carbody with length of 23m. Compos Sci Technol 2006;66(13):2272-83.

[34] Kim J-S, Jeong J-C, Lee S-J. Numerical and experimental studies on the deformational behavior a composite train carbody of the Korean tilting train. Compos Struct 2007;81(2):168-75.

[35] Kim J-S, Chung S-K. A study on the low-velocity impact response of laminates for composite railway bodyshells. Compos Struct 2007;77(4):484-92.

[36] Sun G, Li S, Liu Q, Li G, Li Q. Experimental study on crashworthiness of empty/ aluminum foam/honeycomb-filled CFRP tubes. Compos Struct 2016;152: 969-93.

[37] Hussein RD, Ruan D, Lu G, Sbarski I. Axial crushing behaviour of honeycombfilled square carbon fibre reinforced plastic (CFRP) tubes. Compos Struct 2016;140:166-79.

[38] Liu Q, Fu J, Wang J, Ma J, Chen H, Li Q, et al. Axial and lateral crushing responses of aluminum honeycombs filled with EPP foam. Compos Part B Eng 2017; 130:236-47.

[39] Liu Q, Lin Y, Zong Z, Sun G, Li Q. Lightweight design of carbon twill weave fabric composite body structure for electric vehicle. Compos Struct 2013;97: 231-8.

[40] Eyvazian A, Habibi, M K, Hamouda AM, Hedayati R. Axial crushing behavior and energy absorption efficiency of corrugated tubes. Mater Des 1980- 2015;2014(54):1028-38.

[41] Liu Z, Hao W, Xie J, Lu J, Huang R, Wang Z. Axial-impact buckling modes and energy absorption properties of thin-walled corrugated tubes with sinusoidal patterns. Thin-Walled Struct 2015;94:410-23. 
[42] Singace AA, El-Sobky H. Behaviour of axially crushed corrugated tubes. Int J Mech Sci 1997;39(3):249-68.

[43] Elgalai A, Mahdi E, Hamouda A, Sahari B. Crushing response of composite corrugated tubes to quasi-static axial loading. Compos Struct 2004;66(1): 665-71.

[44] Mahdi E, Mokhtar AS, Asari NA, Elfaki F, Abdullah EJ. Nonlinear finite element analysis of axially crushed cotton fibre composite corrugated tubes. Compos Struct 2006;75(1-4):39-48.

[45] Kılıçaslan C. Numerical crushing analysis of aluminum foam-filled corrugated single- and double-circular tubes subjected to axial impact loading. ThinWalled Struct 2015;96:82-94.

[46] Chen DH, Ozaki S. Numerical study of axially crushed cylindrical tubes with corrugated surface. Thin-Walled Struct 2009;47(11):1387-96.

[47] Abdewi EF, Sulaiman S, Hamouda A, Mahdi E. Quasi-static axial and lateral crushing of radial corrugated composite tubes. Thin-Walled Struct 2008;46(3):320-32.

[48] Eyvazian A, Akbarzadeh I, Shakeri M. Experimental study of corrugated tubes under lateral loading. Proc Institution Mech Eng Part L J Mater Des Appl 2012;226(2):109-18.

[49] Chen D-h. Crush mechanics of thin-walled tubes. CRC Press; 2015.

[50] Wu S, Li G, Sun G, Wu X, Li Q. Crashworthiness analysis and optimization of sinusoidal corrugation tube. Thin-Walled Struct 2016;105:121-34.

[51] Mozafari $\mathrm{H}$, Khatami S, Molatefi $\mathrm{H}$. Out of plane crushing and local stiffness determination of proposed foam filled sandwich panel for Korean Tilting Train eXpress-Numerical study. Mater Des 2015;66:400-11.

[52] Al Galib D, Limam A. Experimental and numerical investigation of static and dynamic axial crushing of circular aluminum tubes. Thin-Walled Struct 2004;42(8):1103-37.

[53] Gu L, Kasavajhala ARM, Zhao S. Finite element analysis of cracks in aging aircraft structures with bonded composite-patch repairs. Compos Part B Eng 2011;42(3):505-10.

[54] Fang J, Sun G, Qiu N, Kim NH, Li Q. On design optimization for structural crashworthiness and its state of the art. Struct Multidiscip Optim 2017;55(3): 1091-119. 